\title{
Novela y relato real en Javier Cercas
}

\author{
Lia Ogno \\ Universidad de Turín
}

\section{RESUMEN:}

El presente artículo pretende indagar la diferencia entre los conceptos de «relato real» y de «novela» en la narrativa de Javier Cercas. Tal distinción se convierte en sumamente relevante a la hora de abordar el esclarecimiento de la novela no-ficcional.

\section{PALABRAS CLAVE:}

Javier Cercas - Relato real - Autoficción - Novela no-ficcional

\begin{abstract}
:
Il presente articolo mira ad indagare la differenza esistente tra i concetti di «racconto reale» e di «romanzo» all'interno dell'opera narrativa di Javier Cercas. Tale distinzione si rivela sommamente efficace al momento di abbordare l'idea di romanzo non-finzionale.
\end{abstract}

PAROLE CHIAVE:

Javier Cercas - Racconto reale - Autofinzione Non-fiction.

El éxito de Soldados de Salamina, éxito de crítica y de público, éxito primero nacional y después, de inmediato o casi, internacional, colocaron a Javier Cercas en la vitrina del reconocimiento de los grandes novelistas de nuestro tiempo, junto a Coetzee, McCarthy, Pamuk, Pennac, Amis, Naipul, Houellebecq, Baricco o Bolaño, por señalar sólo algunos de entre los más indiscutibles. En el año 2001, fecha de publicación de la novela citada, Cercas era todavía un autor escasamente conocido aunque no era poco lo que hasta entonces había publicado. En efecto, a sus casi cuarenta años había publicado ya un libro de relatos, El móvil (1987), del que volvería a editar el relato homónimo en 2003, dos novelas, El inquilino (1989) y El vientre de la ballena (1997), esta última reescrita y publicada de nuevo en 2014, dos volúmenes que recogían buena parte de su actividad periodística, Una buena temporada (1998) y Relatos reales (2000), y un estudio de carácter académico sobre La obra literaria de Gonzalo Suárez (1993). Tal vez nada hacía presagiar el éxito de su sucesiva publicación, tal vez del mismo modo que nada hacía presagiar que el autor de $L a$ Galatea y de un puñado de obras de teatro acaso perdidas fuera a escribir casi veinte 
años después El Quijote, lo cual no deja de explicar, o de aproximar, el secreto de la literatura, el misterio inviolable de la creación artística, pues a la postre la escritura de un autor cualquiera se comprende mejor como camino de escritura, como aprendizaje de un ejercicio de soledad en el que acaso cuente más la consciencia de los desaciertos que la de los propios aciertos.

Soldados de Salamina venía a colocarse de manera casi natural en el campo de interés de la narrativa española por la Guerra Civil, un interés que desde la misma guerra se había mantenido más o menos constante, pero que en la época del cambio de siglo del XX al XXI había crecido de manera considerable ${ }^{1}$. No era casual, desde luego, el renovado interés por la Guerra Civil que manifestaban los entonces jóvenes narradores, pues se correspondía -o se ajustaba o simplemente era coherente- con el nuevo clima intelectual y espiritual que acompañaba en aquellos años a una joven democracia, como era la española de entonces, ya políticamente asentada y más o menos bien consolidada, que podía ahora mirar hacia atrás -hacia el pasado reciente- con mayor atención de lo que, según suele decirse, se había hecho durante el período de la Transición a la democracia ${ }^{2}$. Pero la novela de Cercas, compartiendo ese mismo interés, no era una novela más sobre la Guerra Civil española. Lo explicó el propio Cercas en una amplia entrevista concedida al también escritor italiano Bruno Arpaia: «Mi problema ha sido el de no escribir otra novela sobre la guerra civil, una más de otras muchas» $»^{3}$. Un problema, el de Cercas, que debe ser entendido en sen-

\footnotetext{
${ }^{1}$ Véanse, por ejemplo, M. Bertrand de Muñoz, «La Guerra civil de 1936-1939 en la novela española del último decenio del siglo XX», en Actas del XIII Congreso de la Asociación Internacional de Hispanistas, edición de Florencio Sevilla y Carlos Alvar, tomo II, Madrid, Castalia, 1998, págs. 495503; F. Larraz, «La Guerra civil en la última ficción narrativa española», en Studia histórica. Historia Contemporánea, n. 32, 2014, págs. 345-356. También queremos señalar el capítulo «La Guerra Civil en la novela española del siglo XXI. Panorama», que J.M. Pozuelo Yvancos dedica al tema en su Novela española del siglo XXI, Madrid, Cátedra, 2017, págs. 249-266. En este mismo volumen, el autor profundiza además sobre Cercas, Soldados de Salamina y los conceptos de «autoficción» y «relato real» (págs. 267-277).

2 «Como todo el mundo sabe, la Transición consistió en un pacto mediante el cual los herederos de los derrotados de la guerra renunciaban a pasar cuentas de lo ocurrido durante cuarenta y tres años (que fue el tiempo que duró la guerra civil española, porque la posguerra no fue sino la continuación de la guerra por otros medios), mientras que, en contrapartida, los herederos de los vencedores aceptaban la creación de un sistema político que acogiera a todo el mundo, incluidos los herederos de los derrotados», J. Cercas, «El pasado imposible», en La verdad de Agamenón, Barcelona, Tusquets, 2006, pág. 124. Véase también en propósito S. Juliá, Transición. Historia de una política española (1937-2017), Barcelona, Galaxia Gutenberg, 2017.

${ }^{3}$ «L'avventura di scrivere romanzi. Conversazione con Javier Cercas», en Dedica a Javier Cercas, edición de Bruno Arpaia, Pordenone, Thesis, 2013, pág. 20. « [...] in realtà il romanzo non parla della Guerra civile, anche se essa è uno dei suoi temi e ne costituisce una cornice essenziale. Fondamentalmente, il romanzo parla degli eroi, della possibilità dell'eroismo; parla dei morti, e del fatto che i
} 
tido positivo, como el problema que se pone un autor a la hora de abordar la novela que quiere escribir, que es, claro está, un problema fundamentalmente de forma -de forma narrativa-. No era, en efecto, una novela más sobre la Guerra Civil española, sino una novela que introducía una suerte de cambio de perspectiva en el tratamiento narrativo de ese tema mayor de la literatura española contemporánea. Ese cambio de perspectiva no hacía referencia al tema de la novela, sino, como queda dicho, a la forma narrativa de la misma.

Hay que decir que el fulgurante éxito de Soldados de Salamina propició algunas que otras lecturas críticas apresuradas que acabaron proyectando la novela sobre un debate tal vez impropio e inadecuado o, cuanto menos, confinándola en un horizonte sustancialmente reduccionista que limitaba considerablemente el problema formal que Cercas había desarrollado dando protagonismo a la praxis de la escritura autoficcional. La más sonada fue la polémica entre Arcadi Espada y el propio Javier Cercas alrededor de algunos conceptos centrales de la poética clásica y de su revisitación postmoderna: poesía vs. historia, verdad vs. ficción, etc. ${ }^{4}$ Sobre la áspera polémica entre Cercas y Espada y sobre los distintos flecos que dejó colgando vino a pesar, además, un equívoco relativo al concepto de «relato real» del que se hacía uso en la novela y que, a su vez, se hacía eco de una experiencia previa de naturaleza periodística que Cercas había recogido en volumen y publicado un año antes con el título de Relatos reales. El equívoco consistió en suponer que la novela de Cercas en cuestión, Soldados de Salamina, era sin más un relato real, o que la comprensión de la novela en Cercas hacía equivalentes las categorías de novela y de relato real. De tal equívoco vale la pena reproducir una cita muy conocida del segundo de los artículos de Arcadi Espada: «[...] como si esos personajes [se refiere a Don Quijote, Lázaro y Robinsón] no hubieran recorrido para siempre la dirección contraria a la de sus trolas, es decir, como si no hubieran ido de la ficción a lo real, al igual que hace cualquier empresa novelística triunfante que no llore como relato real lo que no supo defender como ficción» ${ }^{5}$. Bien es cierto que todo aquel malentendido que acompañó sonoramente a la publicación primero de Soldados de Salamina y ocho años después de Anatomía de un instante iba a deshacerse en el 2016 con la publicación

morti non sono morti del tutto fino a quando c'è qualcuno che li ricorda; Parla della ricerca del padre, di Telemaco in cerca di Ulisse; parla dell'inutilità della virtù e della letteratura come unica forma di salvezza; parla del ritrovamento del gusto della vita; e parla della dignità morale», id., págs. 21-22.

${ }^{4}$ Sobre la polémica entre Cercas y Espada, iniciada con la publicación de Soldados de Salamina y renovada tras la publicación de Anatomía de un instante, hay abundante bibliografía; puede verse en propósito J. M. Ruiz Martínez, Poesía frente a historia. Una polémica entre Javier Cercas y Arcadi Espada, Berna, Peter Lang, 2013.

${ }_{5}^{5}$ A. Espada, «Triple y trola. Aproximación al mundo de Javier Cercas (y II)», en Diarios, Madrid, Espasa, 2002, pág. 222. 
de El punto ciego, volumen en el que Cercas recogía los textos de las Conferencias Weidenfeld pronunciadas en la Universidad de Oxford el año anterior. Allí Cercas reflexiona sobre su propia obra y pone al descubierto la teoría de la novela a la que se acoge, aunque acaso sería más exacto decir que esa teoría de la novela allí expuesta es el resultado de una ajustada reflexión sobre la praxis narrativa por él conducida en el tiempo.

\section{EI «relato real» como crónica}

Acaso más que definir qué sea un relato real tenga mayor interés crítico aportar las distintas respuestas que el propio Javier Cercas ha ido modulando en el tiempo a esa pregunta recurrente que de manera explícita o implícita le ha acompañado desde la publicación de Soldados de Salamina: ¿qué es un relato real? En el prólogo a Relatos reales Cercas no duda en vincular los textos allí recogidos al género literario de la crónica: «Este libro reúne un puñado de crónicas. Tratan un poco de todo: [...] de esto, lo otro y lo de más allá» ${ }^{6}$. Decía allí también que el libro podía ser leído como un «dietario azaroso y desordenado», y aducía en favor la razón de que en la sucesión de las crónicas que lo componían se hablaba «ante todo del yo», aclarando después, en ese mismo primer y denso párrafo del prólogo, que «ese yo no soy yo, evidentemente», porque a la postre -decía entonces- «escribir consiste, entre otras cosas, en fabricarse una identidad» ${ }^{7}$. Cabe señalar que el prólogo de Cercas está orientado más a la justificación de esa suerte de ingeniería de la identidad, propia de la postmodernidad, que es la autoficción que a la definición o esclarecimiento de qué sea, en propiedad, un relato real. Sólo hacia el final del prólogo, una vez que el yo («esa bestia omnívora e insoslayable que es el Yo» ${ }^{8}$ ) de la autoficción ha quedado justificado, Cercas recupera el hilo abandonado de la crónica y reivindica su carácter mestizo: «toda buena crónica aspira a participar de una triple condición: la del poema, la del ensayo y la del relato. Más humildes -o más incapaces-, las mías renuncian de antemano a las dos primeras categorías; en sus mejores momentos, propenden tal vez a la última. De hecho, acaso puedan leerse, una a una, como relatos. Como relatos reales. No porque hablen de la realeza -qué más quisiera yo-, sino porque se ciñen a la realidad» ${ }^{9}$. Cercas no podía imaginarse entonces cuánto iba a ser importante aclarar el significado que él daba a ese «ceñirse a la realidad» al que en su decir aspiraban sus relatos reales. Todo parecía indicar que se trataba de ajustarse

\footnotetext{
${ }^{6}$ J. Cercas, Relatos reales, Barcelona, Acantilado, 2005, pág. 7.

${ }^{7}$ Ibid.

8 J. Cercas, La verdad de Agamenón, Barcelona, Tusquets, 2006, pág. 15.

9 J. Cercas, Relatos reales, op. cit., pág. 16.
} 
a la realidad, de amoldarse a ella y discurrir pegado. Pegado a la realidad, evitando, en tanto que relato, cualesquiera formas de alejamiento o separación (de la realidad). En cualquier caso, Cercas dejaba claro que sus crónicas eran -o querían ser- relatos. O de otro modo, que acaso se olvidó tras la publicación de Soldados de Salamina, que los relatos reales son fundamentalmente crónicas, y que, como tales crónicas, deben ser leídos y comprendidos dentro de la especificidad de dicho género literario.

Un relato real es «casi un oxímoron», dirá después en el intento de definición más riguroso de ese primer momento: «un relato real es apenas concebible, porque todo relato, lo quiera o no, comporta un grado variable de invención; o dicho de otro modo: es imposible transcribir verbalmente la realidad sin traicionarla» (pág. 16). Y añade: «Todo relato parte de la realidad, pero establece una relación distinta entre lo real y lo inventado: en el relato ficticio domina esto último; en el real, lo primero. Para crear la suya propia, el relato ficticio aspira a emanciparse de la realidad; el real, permanecer cosido a ella. Lo cierto es que ninguno de los dos puede satisfacer su ambición: el relato ficticio siempre mantendrá un vínculo cierto con la realidad, porque de ella nace; el relato real, puesto que está hecho de palabras, inevitablemente se independiza en parte de la realidad» (pág. 17). Quedaba claro, pues, que el Cercas de esta primera hora era bien consciente de que la oposición entre relato ficcional y relato real obedecía a una voluntad analítica que poco se correspondía con la realidad efectiva de la literatura: ambos tipos de relato -el ficcional y el real- señalan hacia tipologías ideales, pero la realidad de cada uno de ellos manifiesta sus respectivas limitaciones. Con todo, ambas tipologías ideales apuntan en direcciones opuestas y obedecen a distintas reglas de juego (literario), aunque a la postre nada impide que puedan incluso compartir objetivos comunes. El relato real de Cercas, de este modo, venía a colocarse o a converger con algunas prácticas literarias que desde la mitad del siglo pasado, pero de manera creciente en las dos últimas décadas, venían cuestionando de distinto modo el rol preponderante de la ficción en la literatura.

Trece meses después de la publicación de las crónicas de Relatos reales veía la luz la novela Soldados de Salamina. No es aventurado pensar que la escritura del prólogo de Relatos reales se solapó a la escritura de Soldados de Salamina. El equívoco al que antes aludíamos nace del hecho de que en la novela se habla del relato real, o mejor, varios personajes, en ella, razonan sobre el concepto de relato real. Tal sucede, por ejemplo, en la primera parte de la novela, en el diálogo entre el historiador Miquel Aguirre y el periodista Javier Cercas (ambos, resulta superfluo señalarlo, personajes literarios de la ficción novelesca que es Soldados de Salamina): «Me gustó - dice Aguirre en referencia a un artículo de Cercas- porque era como un relato concentrado, sólo que con personajes y situaciones reales... Como un relato real» ${ }^{10}$.

\footnotetext{
${ }^{10}$ J. Cercas, Soldados de Salamina, Barcelona, Tusquets, 2001, pág. 37.
} 
Sucede que el artículo en cuestión del que hablan en la novela los personajes Aguirre y Cercas había sido efectivamente publicado por el autor Javier Cercas en el diario El País el 11 de marzo de 1999 con el título de «Un secreto esencial». Sucesivamente dicho artículo había sido recogido en la tercera sección del volumen Relatos reales y finalmente había sido reproducido en la novela Soldados de Salamina. Tal ingenioso proceder constituye un buen ejemplo del mecanismo autoficcional de Cercas, sin duda, pero aquí, a nuestros efectos, conviene señalar que esa mezcla de realidad y ficción de la novela no supone ningún intento de engaño ominoso hacia el lector, sino, más bien, la reclamación de una lectura exigente. Hay, en efecto, un detalle que no debe pasar desapercibido al crítico que quiera remontarse genéticamente al proceso de escritura de la novela: el artículo de El País se publicó en la fecha del 11 de marzo de 1999, mientras que en la novela ese dato se altera: «Cuando se publicó, el 22 de febrero de 1999, exactamente sesenta años después de la muerte de Machado en Colliure, exactamente sesenta años y veintidós días después del fusilamiento de Sánchez Mazas en el Collell [...]» (pág. 26). Esta disparidad en la fecha advierte no tanto de una imprecisión del personaje literario que es Cercas en la novela, cuanto de la introducción del procedimiento autoficcional por parte del novelista que es Cercas. El personaje de Aguirre da el nombre de relato real a lo mismo que el autor Cercas, es decir, a una de sus crónicas aparecidas primero en la prensa y luego recogidas en el volumen Relatos reales. Aguirre, por tanto, no se refiere a la novela en curso de escritura que es la trama de la novela de Cercas, sino a la crónica aparecida en la prensa.

Más adelante en la novela, en esa ficción novelesca construida precisamente en un juego de espejos en el que se cuestionan los límites de la realidad y la ficción, el personaje de Cercas reflexiona sobre la novela que quiere escribir: «decidí también que el libro que iba a escribir no sería una novela, sino sólo un relato real, un relato cosido a la realidad, amasado con hechos y personajes reales» (pág. 52). Pensar que lo dicho aquí por el personaje literario que es Cercas en la novela puede ser identificado sin más con el propósito del autor de la novela es simplemente un despropósito que contraviene las reglas más elementales de la literatura. Nada justifica la identificación del propósito del personaje con el del autor. Es más, hay no pocos detalles en el mecanismo autoficcional que los separan y alejan considerablemente. Lo único que queda claro es que el personaje literario de Cercas opone relato real a novela: él no quiere escribir una novela, sino «sólo-dice- un relato real». Y es precisamente el empleo de ese adverbio (sólo) lo que abre la pista a una consideración sobre la relación entre novela y relato real. Pero tal cosa -no puede olvidarse- es algo interno a la novela, algo que pertenece a la economía novelesca. El mismo personaje de Cercas, en otra ocasión, haciendo balance crítico de sus investigaciones, emplea el término 
«novelerías» en sentido despectivo (pág. 65): la novelería sería algo así como un relato o narración desprovistos de la prueba de la verdad, del ajuste documental a la realidad de los hechos consumados (novelería tendría que ver con invención y fantasía, pero no con verdad y certeza probadas). En breve: el relato real que quiere escribir el personaje de Cercas en la novela no es la novela que escribe el autor Cercas. Como mucho puede decirse que la novela Soldados de Salamina contiene dentro de sí el intento de escribir autoficcionalmente un relato real, e incluso que ese relato real es la segunda parte de la novela, también titulada «Soldados de Salamina» (la primera se titula «Los amigos del bosque» y la tercera «Cita en Stockton»).

Cabe notar que lo que en el prólogo de Relatos reales aparecía como el deseo o la necesidad del relato real de «ceñirse a la realidad» en Soldados de Salamina cambia y pasa a deseo o necesidad de estar «cosido a la realidad». Ceñir y coser. Ceñirse y coserse. No es, desde luego, una definición precisa, pero la semántica de ambos verbos se aproxima bastante al objetivo perseguido como poética del relato real.

El tercer momento importante en que se habla del relato real en la novela es en la tercera parte, en el diálogo entre Bolaño y Cercas, a la sazón convertidos ambos en personajes literarios de la novela en cuestión: Cercas llama por teléfono a Bolaño y le cuenta lo que anda investigando sobre el fusilamiento de Sánchez Mazas. « $i C h u-$ cha, Javier! -exclamó Bolaño-. Ahí tienes una novela cojonuda» (pág. 166). A lo que Cercas responde: «no es una novela. Es una historia con hechos y personajes reales. Un relato real». Bolaño cierra de este modo: «Da lo mismo. Todos los buenos relatos son reales, por lo menos para quien los lee, que es el único que cuenta». Bolaño no entra en la disquisición teórica de Cercas, en la distinción entre novela y relato real, sino que desplaza la argucia de Cercas al territorio del lector: la literatura no está en lo que hace un autor, sino en lo que hacen los lectores de sus libros. La distinción entre Bolaño y Cercas representa en la novela dos formas de concebir la literatura de nuestro tiempo. Tal distinción se muestra pocas páginas más adelante en la forma de proceder de ambos ante un mismo problema narrativo. Cercas vuelve a llamar a Bolaño y le pone al corriente de su infructuosa búsqueda de Miralles: «le pregunté si se le ocurría alguna otra pista por donde seguir buscando. No se le ocurría ninguna» (pág. 169). Pero el escritor de novelas que es Bolaño en la novela de Cercas no se rinde por ello y sorprende al Cercas autor de relatos reales de la novela: «Tendrás que inventártela», dice Bolaño. «¿Qué cosa?, le pregunta Cercas. "La entrevista con Miralles -le responde Bolaño-. Es la única forma de que puedas terminar la novela". Bolaño sigue erre que erre con que se trata de una novela. A lo que Cercas añade: «Renunciando a recordarle de nuevo a Bolaño que mi libro no quería ser una novela, sino un relato real, y que inventarme la entrevista con Miralles equivalía a traicionar su naturaleza, suspiré» (pág. 170). El suspiro se acompaña con un «Ya», del que 
dice: «La respuesta era lacónica, no afirmativa; pero no lo entendió así Bolaño». En efecto, Bolaño vuelve a la carga: «Es la única forma -repitió, seguro de haberme convencido-. Además, es la mejor. La realidad siempre nos traiciona; lo mejor es no darle tiempo y traicionarla antes a ella. El Miralles real te decepcionaría; mejor inventártelo: seguro que el inventado es más real que el real». Es obvio que el Cercas personaje de la novela no se pliega al consejo de Bolaño, pues para él -quizá en esto de manera similar al autor que es Cercas en esta novela y en otras de parecida índole, como son Anatomía de un instante, El impostor o El monarca de las sombras, novelas todas ellas que responden a un claro intento de redefinición de lo ficcional y de cuestionamiento del rol de la ficción en la literatura contemporánea- la invención es algo que cae fuera de su propia comprensión de la literatura, o, por lo menos, fuera de la poética del relato real. Lo cual no quiere decir, claro está, que el relato real no recurra a la conjetura y a la elaboración de hipótesis razonables. La misma novela, en su segunda parte, nos advertía de ello: «lo que a continuación consigno no es lo que realmente sucedió, sino lo que parece verosímil que sucediera; no ofrezco hechos probados, sino conjeturas razonables» (pág. 89).

En 2006 apareció un nuevo volumen que, como en el caso de Relatos reales, recogía buena parte de las colaboraciones periodísticas de los últimos años de Javier Cercas: La verdad de Agamenón. En la estructura del volumen hay una sección que se titula «Nuevos relatos reales» que reclama una suerte de continuidad con el libro del año 2000. En el prólogo se dice que: «En la medida en que pretenden adscribirse al género de la crónica y ceñirse a la realidad hasta donde tal cosa es posible (o aconsejable), muchas de las piezas incluidas en este libro podrían denominarse relatos reales, una etiqueta al parecer escurridiza que puse hace unos años a un libro de crónicas» ${ }^{11}$. Se incluyen en el citado libro un par de artículos: «La dignidad de la novela» $\mathrm{y}$ «Sobre el arte de la novela (Respuesta a Félix de Azúa», el primero publicado anteriormente en el suplemento Babelia del diario El País, y el segundo en Letras Libres. En ellos Cercas reflexiona sobre el género de la novela y sobre su propia concepción de la misma, cosa que encontrará años después un desarrollo más amplio y mejor estructurado en los textos de las conferencias incluidos en El punto ciego. En La verdad de Agamenón hay también un artículo inicialmente publicado en la revista Quimera (noviembre 2005) sumamente interesante para nuestro propósito: se titula «Sobre las desventajas de no atender en la escuela» y aborda un intento de definición del relato real. «Me pide Fernando Valls, director de Quimera, que explique qué cosa es un relato real. No hay (o no debería haber) mucho que explicar. Acuñé ese marbete, sólo a medias en serio, y a lo que se ve un tanto temerariamente, para acoger bajo su protección un puñado de crónicas -textos de naturaleza híbrida, que a su modo,

\footnotetext{
${ }^{11}$ J. Cercas, La verdad de Agamenón, op. cit., pág. 19.
} 
como tal vez toda crónica, aspiraban a participar de la condición del poema, de la del ensayo y, quizá sobre todo, de la del relato» (pág. 111). No estaría de más, desde luego, prestar atención a la confesión de Cercas de haberlo acuñado medio en serio y temerariamente, pues quizá contribuya no poco a superar el equívoco -del que el propio Cercas declara en ese mismo prólogo ser consciente- que acompañó desde el inicio al concepto de relato real y a esclarecer el horizonte de acción (literaria) en el que se colocaba Cercas entonces.

El artículo «Sobre las desventajas de no atender en la escuela», después de recoger en cita explícita algunos párrafos del prólogo de Relatos reales, lleva a cabo un intento de dar una vuelta de tuerca más al ejercicio de comprensión y definición del relato real: «un relato real es el que surge de una conciencia lo más acusada posible de sus limitaciones [...] y empieza a operar una vez se ha hecho cargo de ellas y, por así decirlo, sin perderlas nunca de vista. En un sentido laxo, un relato real sería una especie de crónica o reportaje escrito por alguien que, pese a perseguir encarnizadamente la verdad de los hechos, posee la suficiente conciencia de su oficio como para conocer las limitaciones de su instrumental, que carece de las potencialidades de la ciencia, y la suficiente humildad -o el suficiente ímpetu o entusiasmo- como para seguir trabajando a partir de ello, pero sobre todo a pesar de ello. Simplificando al máximo, un relato real vendría a ser, pues, una historia empeñada en ser verdadera, rigurosamente verdadera, capaz de acoger en su tejido todos los matices infinitos de la infinita complejidad de lo real, escrita por quien sabe que escribir esa historia no está a su alcance, ni al de nadie si se exceptúa a Dios, que no existe» (pág. 112). Importa resaltar aquí esa vinculación con la verdad a la que se hace referencia, algo que, sin duda, hunde sus raíces en la citada polémica con Arcadi Espada, y que, sucesivamente, iba a tener un desarrollo orgánico en la teoría de la novela que es $E l$ punto ciego. En cualquier caso, el propio Cercas intenta aquí correr al reparo de los equívocos suscitados por el concepto de relato real: «En apariencia, la plasmación más extensa de la idea de relato real se halla, al menos en lo que a mi trabajo respecta, en mi novela Soldados de Salamina. Digo en apariencia porque la verdad es que Soldados de Salamina no es, ni pretende ser, un relato real, sino sólo una novela -sea esto lo que sea-, cosa que ahora no es el momento de discutir» (pág. 112).

\section{Novela: punto ciego y tercera verdad}

Nueve novelas componen, hasta el momento, la obra narrativa de Javier Cercas. De ellas, cinco se acogen a un procedimiento ficcional, mientras que las cuatro restantes se construyen precisamente desde el cuestionamiento de tal proceder literario. Al Cercas ficcional pertenecen: El móvil (1987), El inquilino (1989), El vientre de la 
ballena (1997), La velocidad de la luz (2005) y Las leyes de la frontera (2012). Al Cercas no-ficcional, en cambio, pertenecen: Soldados de Salamina (2001), Anatomía de un instante (2009), El impostor (2014) y El monarca de las sombras (2014). Como puede verse fácilmente de la cronología de las novelas, Cercas alterna ambos procedimientos, por lo que sería apresurado -e inexacto- pensar que lo que sucede en la narrativa de Cercas es una suerte de punto de inflexión (representado por Soldados de Salamina) a partir del cual su narrativa derivaría hacia la no-ficción. No es así, desde luego, y ello hace que no fuera simple, ni fácil, desentrañar una teoría de la novela que a la postre alimenta tanto el procedimiento ficcional como el noficcional. La publicación en 2016 de El punto ciego vino en este sentido a dar una contribución fundamental, pues es allí que Cercas hace explícita de manera orgánica (alusiones y algún destello, como punta de un iceberg, habían aparecido en alguno de los artículos contenidos en La verdad de Agamenón) su particular teoría de la novela.

En «La tercera verdad», el primero de los ensayos contenidos en El punto ciego, después de haber reclamado la herencia inagotable de Cervantes y del Quijote para la novela y de haber inventado - al modo borgiano- su propia tradición novelesca, Cercas, reflexionando sobre lo que fue la escritura de la segunda de sus novelas no-ficcionales, Anatomía de un instante (aunque, por lo demás, nada empece para que sus consideraciones del caso no puedan hacerse extensivas al conjunto de su narrativa, incluidas las novelas ficcionales), afirma lo siguiente: «mi preocupación capital mientras escribía el libro, en fin, fue la forma, y un escritor en general -y un novelista en particular- es ante todo alguien concernido por la forma, alguien que siente que en literatura la forma es el fondo y que piensa por ello que sólo a través de la forma -a través de la reescritura y reelaboración virtualmente inacabables de las frases y la estructura de un libro- es posible acceder a una verdad que de otro modo resultaría inaccesible» ${ }^{12}$. La cita carece de desperdicio, desde luego, pero quizá lo más interesante para nosotros ahora sea el reconocimiento del primado de la forma y la vinculación de la novela al descubrimiento de la verdad, o, cuanto menos, de una verdad que, de otro modo, quedaría oculta. La novela, y por ende la literatura, no queda confinada en la zona del ocio y del entretenimiento ciudadano, ni siquiera a la fruición y disfrute de la belleza, sino que alberga un particular modo de conocimiento relacionado con la persecución de la verdad. Y conviene notar que en la división de los saberes propios del orden occidental la verdad era algo que iba asociado al cultivo de las ciencias y de la filosofía, no al arte ni a la literatura. Vuelve sobre ello más adelante: «la novela no es un entretenimiento (o no sólo es eso); es, sobre todo, una herramienta de investigación existencial, un utensilio de conocimiento de lo humano» (pág. 46). La novela es conocimiento. La literatura en general y la novela en

\footnotetext{
${ }^{12}$ J. Cercas, El punto ciego, Barcelona, Penguin Random House, 2016, págs. 37-38.
} 
particular ${ }^{13}$ son formas del humano conocimiento, un conocimiento desconsiderado en el orden de los saberes construido en Occidente a lo largo de la historia, un conocimiento distinto del de las ciencias y la filosofía, alejado de su seguridad y de la claridad y distinción que reclamaba Descartes en el despertar de la época moderna, pero conocimiento al fin. No mero entretenimiento y diversión, sino saber experiencial al que se accede desde la experiencia de la lectura. «No es verdad que la única obligación de una novela sea contar una buena historia y hacérsela vivir al lector; la única obligación de una novela (o por lo menos la más importante) consiste en ampliar nuestro conocimiento de lo humano» (pág. 47).

Parece natural pensar que el cruce del horizonte de la verdad con el de la novela tiene que ver con esa producción narrativa que antes hemos identificado con la del Cercas no-ficcional. Veremos que no es así, porque la verdad literaria es algo que puede ser reivindicado tanto desde el procedimiento no-ficcional como desde el ficcional. Ahora bien, centrándonos en el primero, donde, como queda dicho, el vínculo aparece más evidente, y con referencia a Anatomía de un instante, hay un punto en el que Cercas, a partir de la distinción de la Poética aristotélica entre poesía e historia, distingue entre la verdad de la historia y la verdad de la literatura. La primera vendría a ser una «verdad factual, concreta, particular, una verdad que busca fijar lo ocurrido a determinados hombres en un determinado momento y lugar», mientras que la segunda, «la verdad de la literatura (o de la poesía, que es como llama a la literatura Aristóteles) sería una verdad moral, abstracta, universal, una verdad que busca fijar lo que nos pasa a todos los hombres en cualquier momento y lugar» (pág. 48). En el caso concreto de Anatomía de un instante (extensible sin problemas al resto de la narrativa no-ficcional), Cercas dice haber perseguido «al mismo tiempo esas dos verdades antagónicas», la verdad factual y la verdad moral, en una suerte de juego de trasvases de la una a la otra en el que «idealmente, la verdad histórica ilumina a la verdad literaria y la verdad literaria ilumina a la verdad histórica, y donde el resultado no es ni la primera verdad ni la segunda, sino una tercera verdad que participa de ambas y que de algún modo las abarca» (pág. 49). Un poco más adelante llama a esta tercera verdad de sus novelas no-ficcionales «tercera verdad conjetural».

Cabe preguntarse si esta tercera verdad conjetural constituye el soporte de la teoría de la novela de Cercas, porque, de ser así, todo parecería indicar que habría en

\footnotetext{
${ }^{13}$ No quiero aquí adentrarme en el terreno más escurridizo de la poesía, donde el tema de la obra artística como forma o herramienta del conocimiento ha dado mucho de que hablar, baste con recordar la polémica protagonizada en los años 50 del siglo pasado por Aleixandre-Bousoño y Valente-Barral, entre otros. O las elocuentes palabras pronunciadas por Federico García Lorca en su renombrado Recital-Conferencia sobre el Romancero gitano: «El hombre se acerca por medio de la poesía con más rapidez al filo donde el filósofo y el matemático vuelven la espalda en silencio».
} 
él una suerte de privilegio de su producción no-ficcional sobre la ficcional. Veremos que no es así, pues lo importante de su teoría de la novela no es tanto el concepto de tercera verdad (definitorio de la relación, propia de la novela no-ficcional, entre verdad histórica y verdad literaria) cuanto el concepto de punto ciego, a cuyo través vuelve a brillar esa verdad moral propia de la literatura a la que obedece y a la que se pliega toda -insisto: toda, tanto la no-ficcional cuanto la ficcional- su obra. Lo aclara Cercas en el prólogo de El punto ciego, en un paso que busca desvelar la unidad profunda de los distintos ensayos del libro: «Del diálogo que he mantenido en público conmigo mismo durante los últimos años surge la mayor parte de lo que se dice en este libro. En él se razona sobre asuntos dispares, pero siempre relacionados con la naturaleza de la novela, en particular de la novela del siglo XXI, así como con el papel del novelista; tarde o temprano, sin embargo, todos esos asuntos acaban confluyendo en una idea central; esa idea entraña una teoría de la novela (y en cierto modo también del novelista): la teoría del punto ciego» (págs. 16-17). Después explica el origen de dicha expresión y la remite a la anatomía del ojo: el punto ciego nombra un lugar del disco óptico a cuyo través no se ve nada porque carece de detectores de luz. Es decir, que el punto ciego remite a una zona de oscuridad, una zona invisible para el ojo en cuestión. Si tal zona de oscuridad no se percibe se debe a que la visión humana es biocular y los puntos ciegos de cada ojo no son coincidentes. Pero también, acaso sobre todo, porque la teoría de la visión otorga al cerebro un papel nada despreciable que consiste en suplir -no casualmente, claro está, sino en base a un aprendizaje experiencial- lo que el ojo no es capaz de ver por sí solo. Aplicado a la novela, a las novelas que Cercas llama de punto ciego, vendría a ser como sigue: «En el centro de estas novelas hay siempre un punto ciego, un punto a través del cual no es posible ver nada. Ahora bien -y de ahí su paradoja constitutiva-, es precisamente a partir de ese punto ciego a través del cual, en la práctica, estas novelas ven; es precisamente a partir de esa oscuridad a través de la cual iluminan estas novelas; es precisamente a partir de ese silencio a partir del cual estas novelas se tornan elocuentes» (pág. 17). Algo así como escuchar lo que se cela en el silencio, como ver o empezar a vislumbrar no sólo y no tanto lo que permanece oculto y en la sombra, sino la misma sombra, la oscuridad misma. «Podríamos decirlo de otra manera. En cierto modo el mecanismo que rige las novelas del punto ciego es muy similar, si no idéntico: al principio de todas ellas, o en su corazón, hay siempre una pregunta, y toda la novela consiste en una búsqueda de respuesta a esa pregunta central; al terminar esa búsqueda, sin embargo, la respuesta es que no hay respuesta, es decir, la respuesta es la propia búsqueda de una respuesta, la propia pregunta, el propio libro. En otras palabras: al final no hay una respuesta clara, unívoca, taxativa; 
sólo una respuesta ambigua, equívoca, contradictoria, esencialmente irónica, que ni siquiera parece una respuesta y que sólo el lector puede dar» (págs. 16-17).

Es muy interesante este juego casi sinestésico que vincula en la teoría de la novela de Cercas el orden de la pregunta y la ausencia de respuestas a la zona oscura de la visión. Pero interesa notar, sobre todo, que la teoría del punto ciego abre el espacio de la novela al libre despliegue de procedimientos tanto ficcionales como no-ficcionales. En efecto, en «El punto ciego», el segundo de los ensayos del libro homónimo, toda la reflexión de Cercas se hace a partir de la experiencia de escritura de Las leyes de la frontera, una novela que cae decididamente del lado ficcional. La novela se construye desde el centro que representa su pregunta madre (¿quién delató a la banda del Zarco?), de la misma manera que Anatomía de un instante y Soldados de Salamina, por ejemplo, se construyen desde el centro de sus preguntas madre (¿por qué Adolfo Suárez permaneció sentado mientras a su alrededor los militares golpistas disparaban en el Congreso de Diputados el 23 de febrero de 1981?, ¿por qué el soldado republicano que descubrió al huido Sánchez Mazas no lo delató?). Allí declara Cercas que hay un mecanismo narrativo que unifica toda su producción novelística y que éste consiste precisamente en la teoría del punto ciego: «El mecanismo narrativo que las rige [a todas sus novelas] es en el fondo muy semejante. En algún momento de su desarrollo se formula una pregunta, y el resto de la novela consiste, de una forma más o menos visible o secreta, en un intento de responderla, hasta que al final la respuesta es que no hay respuesta» (pág. 54). Parecería natural pensar que si no hay respuestas, que si el resultado final de una novela que se construye como búsqueda de respuesta a una pregunta concreta es que no hay respuesta a tal pregunta, entonces no habría posibilidad alguna de hablar de verdad. De ningún tipo de verdad. Y sin embargo Cercas, como vimos, reivindica el valor de verdad moral de la literatura, que es como decir el valor de verdad de la novela.

Sobre la ausencia de respuesta reflexiona más adelante: «en ninguna de esas novelas [se refiere a las del punto ciego] se da una respuesta clara, taxativa e inequívoca a su interrogante central, sino sólo una respuesta ambigua, equívoca y contradictoria, esencialmente irónica; una respuesta que en realidad no es una respuesta y que sin embargo es el único tipo de respuesta que puede permitir una novela, porque la novela es el género de las preguntas, no el de las respuestas: en rigor, la obligación de una novela no consiste en responder la pregunta que ella misma plantea, sino en formularla con la mayor complejidad posible» (pág. 55). Definir la novela como el género de las preguntas viene a ser lo mismo que reivindicar la teoría del punto ciego como motor de la novela desde su nacimiento con Cervantes hasta nuestros días. Importa resaltar la adjetivación que acompaña en los pasos citados a la novela: ambigua, equívoca, contradictoria, irónica. Así es, en efecto, la obra maestra del Quijote, y por 
eso es tan importante -aunque no siempre se vea o se resalte este aspecto- para el desarrollo de la modernidad, pues el antidogmatismo, el escepticismo y la tolerancia cervantinos, y sus sucesivos desarrollos, han sido uno de los diques de contención del ímpetu orgulloso de una ciencia y una filosofía modernas rebosantes de exceso de seguridad. La novela nos recuerda siempre el punto ciego. «Ese punto ciego es lo que somos» (pág. 18). 